\title{
Rationale, Design, and Profiles of the New Integrated Suburban Seniority Investigation (NISSIN) Project: A Study of an Age-Specific, Community-Based Cohort of Japanese Elderly
}

\author{
Tetsuhisa Kitamura ${ }^{1}$, Takashi Kawamura ${ }^{1}$, Akiko Tamakoshi ${ }^{2}$, Kenji Wakai ${ }^{3}$, \\ Masahiko Ando ${ }^{1}$, and Yoshiyuki Ohno ${ }^{3}$ \\ ${ }^{1}$ Kyoto University Health Service, Kyoto, Japan \\ ${ }^{2}$ Department of Public Health, Aichi Medical University School of Medicine, Nagakute, Aichi, Japan \\ ${ }^{3}$ Department of Preventive Medicine/Biostatistics and Medical Decision Making, Nagoya University Graduate School of Medicine, Nagoya, Japan
}

Received November 20, 2008; accepted April 15, 2009; released online August 1, 2009

\begin{abstract}
Background: Although there have been many studies on aging in a number of developed countries, data on the effects of aging during early senescence are scarce. We designed a study to investigate an age-specific cohort in a suburban Japanese city to determine the factors that contribute to living long and well.

Methods: In every year from 1996 through 2005, residents of Nissin City, Japan who were about to reach the age of 65 years participated in health check-ups and completed a baseline self-administered questionnaire that included items on demographic and lifestyle characteristics, physical function, and quality of life. When the participants reached 70 years of age, they underwent secondary health check-ups at the same site, or received home visits from public health nurses, and their health-related outcomes were noted.

Results: A total of 3073 64-year-olds were enrolled in the study (response rate, 43.9\%). There was considerable intersexual variation in demographic and lifestyle factors. Among men and women, $24.3 \%$ and $3.0 \%$ were current smokers, respectively, and $68.7 \%$ and $19.5 \%$ were current alcohol drinkers. Cohort members were in slightly better physical condition than the Japanese general population: they were less likely to be obese and hypertensive and more likely to have 20 teeth or more. Follow-up of the cohort is ongoing.
\end{abstract}

Conclusions: We have established a unique age-specific cohort with a consecutive entry-exit system. This project should provide data on early changes in health and related factors in this new era of longevity.

Key words: cohort study; elderly; age-specific; physical functioning; quality of life

\section{INTRODUCTION}

In Japan, many people live to an advanced age. ${ }^{1}$ The proportion of people aged 65 years or older has continuously increased, from $4.9 \%$ in 1950 to $21.5 \%$ in 2007 , and it is expected to reach $35.7 \%$ in $2050 .^{2}$ However, the increasing number of elderly people suffering from dementia and depression is becoming a serious problem. Dementia is associated with physical activity ${ }^{3}$ and $\operatorname{diet}^{4}{ }^{4}$ and depression in elders appears to increase mortality ${ }^{5}$ and cognitive deterioration. ${ }^{6}$ Therefore, a positive mental state is a key factor in longevity.

A cohort study is an effective epidemiological method in investigating the association between lifestyle and health events. A number of moderately sized cohort studies have been conducted to evaluate mortality/morbidity and related factors among elderly people, both in $\mathrm{Japan}^{7-12}$ and worldwide. ${ }^{13-18}$ Most participants in such cohorts were old-old, among whom life-threatening events are frequent. However, preclinical changes in the physical and psychosocial status of individuals nearing the end of their seventh decade of life - the beginning of senescence - have been inadequately described.

To evaluate the predictors of mortality, morbidity, and other physical/mental outcomes among younger elderly Japanese, we established an age-specific, prospective cohort that focused on people who would soon reach 65 years of age. We then followed them until they passed their 70th birthday. Herein, we describe the study design and the profiles of cohort participants at baseline. This study has been designated the New Integrated Suburban Seniority Investigation Project (The NISSIN Project). 


\section{METHODS}

\section{Setting and participants}

In 1994, researchers affiliated with the former Department of Preventive Medicine, Nagoya University School of Medicine, designed a community-based, prospective cohort study that was combined with preventive health services in Nissin City, which is located in central Japan near metropolitan Nagoya. Nissin has an area of $34.0 \mathrm{~km}^{2}$ and a population of approximately 60000 in 1995 . Its mean annual population growth rate from 1995 through 2000 was the highest (16.4\%) of any city in Japan. ${ }^{19}$ Because its government has been committed to conducting welfare projects for elderly inhabitants, Nissin was selected as the most suitable community for conducting a study on aging. We launched the prospective cohort in 1996 as part of preventive health services offered by the municipal government.

Using the basic resident registry of the city, residents aged 64 years were invited by letter to a free comprehensive medical and dental check-up in April every year from 1996 through 2005, and the responders were registered as our cohort members. The medical check-up included height and weight; systolic and diastolic blood pressure; dipstick urinalyses; fecal occult blood; laboratory blood testing including blood counting, liver function, serum lipids, and serum creatinine; chest x-ray; upper gastrointestinal fluorography; electrocardiography; and (in women) measurement of calcaneal bone density using dual energy X-ray absorptiometry (through 2004) or dry ultrasonometry (since 2005). All clinical tests were performed at a single laboratory. Concurrently, several mini-tubes $(100-500 \mu \mathrm{L}$ per tube) of plasma from each examinee were stored for future analyses at $-80^{\circ} \mathrm{C}$ in freezers at the Department of Preventive Medicine/Biostatistics and Medical Decision Making, Nagoya University Graduate School of Medicine. The self-administered questionnaire included items on demographic and lifestyle factors, physical function, and quality of life. Demographic factors included sex and year of birth; residential, marital, educational, and work status; source of income; and current history of diseases and medication. Lifestyle factors included smoking status, alcohol consumption, sleep quality, leisure time activities, physical activities, eating habits, and diet. Oral hygiene habits, including frequency of brushing, were included in the questionnaire, and the number of teeth lost (excluding third molars), use of dentures, and periodontal status were noted at the dental examination.

In the section on diet, the questionnaire included items on the frequency of intake for 97 modern Japanese foods and dishes during the 1 month before the baseline survey. This food frequency questionnaire was designed to estimate daily amounts of food group consumption and nutrient intakes, and has been previously validated. ${ }^{20,21}$ Intellectual, physical, and social functioning were evaluated by using the Tokyo
Metropolitan Institute of Gerontology (TMIG) index of competence-a standardized, multidimensional, 13-item index of competence that measures the functional capacity of elderly individuals and has been adapted for and validated in the Japanese population. ${ }^{22,23}$ Quality of life was measured by using the Life Satisfaction Index-K and the shorter version of the Geriatric Depression Scale, with 15 items. The Life Satisfaction Index-K questionnaire measures subjective wellbeing among elderly individuals and consists of 9 items (1 item from the Kutner Morale Scale, ${ }^{24} 5$ items from the revision of the Philadelphia Geriatric Center Morale Scale, ${ }^{25}$ and 3 items from the Life Satisfaction Index- $\mathrm{A}^{26}$ ). The questionnaire has been demonstrated to have sufficient reliability and validity in the Japanese population. ${ }^{27}$ The Geriatric Depression Scale is a self-rating depression screening tool for elderly individuals ${ }^{28,29}$; the shorter version has been validated. ${ }^{30-32}$ In other examinations, the participants underwent physical fitness testing, including sitting trunk flexion; right and left grip strength; one-leg standing with eyes open (from 1996 through 2002); gait performance testing, including step length, pitch, and velocity during comfortable and maximum walking (from 1996 through 2002); cognitive function testing, including the word recall and the delayed word recall task from the Alzheimer's Disease Assessment Scale (ADAS) $)^{33}$ and the forward and backward Digit Span Test from Wechsler Adult Intelligence Scale-Revised (WAIS-R) ${ }^{34}$ (from 1996 through 2001); and a salivary IgA test (from 1998 through 2005).

\section{Follow-up}

Since 2002, we have been conducting annual health checkups similar to those conducted at baseline for city residents aged 70 years. Clinical and laboratory tests of the same items, the cognitive function test (ADAS), and the short questionnaire, which includes an item on the frequency of falls, were offered. The study participants who still resided in the city were able to participate in these health checkups and their study outcomes were then obtained from these measurements. For those who lived in the city but did not participate in these health checkups, at-home interviews were conducted by municipal public health nurses. By using the basic resident register of the city, participant mortality and relocation out of the city were followed. The cause of death was confirmed by using the official death certificate, with the permission of the Ministry of Internal Affairs and Communications of Japan. Visiting municipal public health nurses noted whether cohort members received home nursing care under the public nursing-care insurance system.

\section{Ethical issues}

Eligible respondents gave consent to participate in the study at the site of the health check-up. For the questionnaire survey, oral consent was obtained by using an opt-out approach up to 2001, and written consent by an opt-in approach thereafter. ${ }^{35}$ 
Table 1. Temporal trend in participation for the study

\begin{tabular}{|c|c|c|c|c|c|c|}
\hline Entry year & Year of birth & $\begin{array}{l}\text { Eligible } \\
\text { residents }\end{array}$ & Men & $\begin{array}{c}\text { Participants } \\
\text { Women }\end{array}$ & Total & $\begin{array}{l}\text { Response } \\
\text { rate }\end{array}$ \\
\hline & & $n$ & $n$ & $n$ & $n$ & $\%$ \\
\hline 1996 & 1931 & 540 & 124 & 129 & 253 & 46.9 \\
\hline 1997 & 1932 & 612 & 131 & 134 & 265 & 43.3 \\
\hline 1998 & 1933 & 593 & 131 & 137 & 268 & 45.2 \\
\hline 1999 & 1934 & 637 & 152 & 169 & 321 & 50.4 \\
\hline 2000 & 1935 & 679 & 165 & 158 & 323 & 47.6 \\
\hline 2001 & 1936 & 718 & 208 & 158 & 366 & 51.0 \\
\hline 2002 & 1937 & 823 & 173 & 154 & 327 & 39.7 \\
\hline 2003 & 1338 & 720 & 160 & 173 & 333 & 46.3 \\
\hline 2004 & 1939 & 779 & 142 & 144 & 286 & 36.7 \\
\hline 2005 & 1940 & 903 & 162 & 169 & 331 & 36.7 \\
\hline Total & & 7004 & 1548 & 1525 & 3073 & 43.9 \\
\hline
\end{tabular}

Similarly, for blood sample donation, oral consent was obtained by the opt-out approach up to 1999, and written consent by the opt-in approach thereafter. The study protocol was approved by the Ethics Committee of Nagoya University Graduate School of Medicine (No. 162, 2002 and 2004), the National Center for Geriatrics and Gerontology of Japan (No. 242, 2006), and the Aichi Medical University School of Medicine (No. 558, 2008).

\section{Data analyses}

All data were anonymized, and data cleaning procedures were rigorously conducted by one of the authors (AT). We tabulated the numbers of the participants, along with their proportions and the mean values of measurements, for selected baseline characteristics, by sex. Body mass index was calculated as weight $(\mathrm{kg})$ divided by height $(\mathrm{m})$ squared, and obesity was defined as a BMI of $25.0 \mathrm{~kg} / \mathrm{m}^{2}$ or higher. Hypertension was defined as a measured systolic blood pressure of $140 \mathrm{~mm} \mathrm{Hg}$ or higher, a diastolic blood pressure of $90 \mathrm{~mm} \mathrm{Hg}$ or higher, or self-reported medication for hypertension. Diabetes mellitus was defined as a measured hemoglobin A1c of $6.5 \%$ or higher, fasting plasma glucose of $126 \mathrm{mg} / \mathrm{dl}$ or higher, or self-reported medication for diabetes mellitus. Hyperlipemia was defined as a total cholesterol level of $220 \mathrm{mg} / \mathrm{dl}$ or higher, or selfreported medication for hyperlipemia. Glomerular filtration rate (GFR) was estimated by the Modification of Diet in Renal Disease (MDRD) study equation, modified for Japanese. ${ }^{36}$ According to the guidelines of the Kidney Disease Outcomes Quality Initiative, GFR less than $60 \mathrm{~mL} /$ $\mathrm{min} / 1.73 \mathrm{~m}^{2}$ represents stage 3 to 5 chronic kidney disease. ${ }^{37}$ Cerebrovascular diseases indicated cerebral infarction, cerebral hemorrhage, and subarachnoid hemorrhage; cardiovascular diseases indicated myocardial infarction and angina pectoris; and cancers included solid tumors of the lung, stomach, gall bladder, ovary, uterus, breast, small intestine, colorectum, and liver. We excluded participants with $\log _{\mathrm{e}^{-}}$ transformed energy intake levels beyond 3 standard deviations from the mean value per day by sex from the analyses for nutrition. ${ }^{38}$ The possible total score range in the LSI-K is 0 to 9 , and a higher score indicates greater life satisfaction. ${ }^{27}$ The possible total score range in the TMIG index of competence is 0 to 13 , and a higher score indicates a greater competence level. ${ }^{22,23}$ Although the total GDS-15 score ranges from 0 to 15 and a higher score suggests more severe depression, a total score of 6 or higher was treated as significant depressive tendency. ${ }^{30-32}$ Sex differences were evaluated using the unpaired $t$-test for numerical variables, and the chi-square test for categorical variables. All statistical analyses were carried out using SPSS software (version 16.0J, SPSS, Inc.).

\section{RESULTS}

Table 1 shows the temporal trend in participation for the study. The number of eligible residents aged 64 years increased from 540 in 1996 to 903 in 2005, and totaled 7004. Among the eligible subjects, 3098 participated in the medical check-up, and 3073 participants (43.9\%) were ultimately enrolled in the study, excluding 25 persons who did not provide consent. Nearby half of the eligible residents participated in the study, but the proportion decreased after 2002. A total of 1548 men and 1525 women were enrolled in the study - a sex ratio of approximately 1.0. Among the participants, $2608(84.9 \%)$ underwent a dental examination, $1147(37.3 \%)$ a cognitive function test, 1349 (43.9\%) a fitness test, and $2472(80.4 \%)$ a salivary $\operatorname{IgA}$ test.

Table 2 shows the baseline demographic and lifestyle characteristics of the study participants, by sex. The proportions of current workers, presently married individuals, and high academic achievers were greater among men than among women; the proportions of current smokers and drinkers were markedly greater among men than among women.

Table 3 shows the medical and dental characteristics of the study participants, by sex. Obesity, hypertension, diabetes mellitus, and stage 3 to 5 chronic kidney disease were more common in men than in women. However, the prevalence of hyperlipemia was lower in men than in women. A history of 
Table 2. Selected baseline demographic and lifestyle characteristics of participants, by sex

\begin{tabular}{|c|c|c|c|c|c|}
\hline & \multicolumn{2}{|c|}{$\begin{array}{c}\text { Men } \\
(n=1548)\end{array}$} & \multicolumn{2}{|c|}{$\begin{array}{c}\text { Women } \\
(n=1525)\end{array}$} & \multirow[t]{2}{*}{$P$ value } \\
\hline & $n$ & $\%$ & $n$ & $\%$ & \\
\hline \multicolumn{6}{|l|}{ Demographic status } \\
\hline Currently employed & 863 & 55.7 & 399 & 26.2 & $<0.001$ \\
\hline Presently married & 1469 & 94.9 & 1254 & 82.2 & $<0.001$ \\
\hline College graduate & 451 & 29.1 & 62 & 4.1 & $<0.001$ \\
\hline \multicolumn{6}{|l|}{ Lifestyle factors } \\
\hline Current smoker & 376 & 24.3 & 45 & 3.0 & $<0.001$ \\
\hline Ex-smoker & 502 & 32.4 & 52 & 3.4 & $<0.001$ \\
\hline Current drinker & 1061 & 68.5 & 298 & 19.5 & $<0.001$ \\
\hline
\end{tabular}

Table 3. Selected baseline medical and dental characteristics of participants, by sex

\begin{tabular}{|c|c|c|c|c|c|}
\hline & \multicolumn{2}{|c|}{ Men } & \multicolumn{2}{|c|}{ Women } & \multirow{2}{*}{$P$ value } \\
\hline & $n$ & $\%$ & $n$ & $\%$ & \\
\hline \multicolumn{6}{|l|}{ Medical status } \\
\hline Obesity $^{a}$ & 384 & 24.8 & 306 & 20.1 & $<0.001$ \\
\hline Hypertension ${ }^{b}$ & 781 & 50.5 & 599 & 39.3 & 0.002 \\
\hline Diabetes mellitus ${ }^{c}$ & 197 & 12.8 & 95 & 6.2 & $<0.001$ \\
\hline Hyperlipemia $^{d}$ & 499 & 32.3 & 894 & 58.6 & $<0.001$ \\
\hline $\begin{array}{l}\text { Chronic kidney disease } \\
\quad(\text { stage } 3-5)^{\mathrm{e}}\end{array}$ & 385 & 24.9 & 315 & 20.7 & 0.006 \\
\hline \multicolumn{6}{|l|}{ History of } \\
\hline Cardiovascular diseases & 77 & 5.0 & 36 & 2.4 & $<0.001$ \\
\hline Cerebrovascular diseases & 62 & 4.0 & 39 & 2.6 & 0.026 \\
\hline Cancers & 40 & 2.6 & 36 & 2.4 & 0.729 \\
\hline \multicolumn{6}{|l|}{ Dental status } \\
\hline Brushing $\geq 3$ times/day & 165 & 12.7 & 259 & 20.7 & $<0.001$ \\
\hline Number of teeth present $\geq 20$ & 896 & 77.4 & 849 & 75.3 & 0.323 \\
\hline
\end{tabular}

aody mass index $\geq 25.0 \mathrm{~kg} / \mathrm{m}^{2}$.

bystolic blood pressure $\geq 140 \mathrm{~mm} \mathrm{Hg}$, diastolic blood pressure $\geq 90 \mathrm{~mm} \mathrm{Hg}$, or medication for hypertension.

'Hemoglobin A1c $\geq 6.5 \%$, fasting plasma glucose $\geq 126 \mathrm{mg} / \mathrm{dl}$, or medication for diabetes mellitus.

${ }^{\mathrm{d}}$ Total cholesterol $\geq 220 \mathrm{mg} / \mathrm{dl}$ or medication for hyperlipemia.

e GFR $\leq 60.0 \mathrm{ml} / \mathrm{min} / 1.73 \mathrm{~m}^{2}$, as estimated by the MDRD study equation, modified for Japanese.

cardiovascular diseases and a history of cerebrovascular diseases were more frequent in men than in women. The prevalence of cancers was similar between sexes. The frequency of tooth brushing at least 3 times per day was higher in women than in men. Approximately $75 \%$ of the male and female participants had 20 teeth or more.

Table 4 shows dietary intakes of representative foods and nutrients among the study participants. Although energy intake was similar between sexes, intake of all nutrients was lower in men than in women, except for alcohol. Table 5 shows the baseline aging-related psychosocial state of the study participants. The scores were similar between sexes, but the proportion with depressive tendency was slightly smaller in men than in women. Both male and female participants had very high scores in the TMIG index of competence.
Table 4. Selected baseline nutritional characteristics of participants, by sex ${ }^{a}$

\begin{tabular}{|c|c|c|c|c|c|}
\hline & \multicolumn{2}{|c|}{$\begin{array}{c}\text { Men } \\
(n=1481)\end{array}$} & \multicolumn{2}{|c|}{$\begin{array}{l}\text { Women } \\
(n=1460)\end{array}$} & \multirow{2}{*}{$P$ value } \\
\hline & Mean & $S D^{c}$ & Mean & $S D^{c}$ & \\
\hline Energy (kcal) ${ }^{b}$ & 1910.5 & 601.7 & 1910.3 & 611.6 & 0.804 \\
\hline Fat $(g)$ & 50.1 & 21.7 & 57.2 & 24.0 & $<0.001$ \\
\hline Protein (g) & 69.1 & 26.0 & 77.6 & 29.5 & $<0.001$ \\
\hline Carbohydrate (g) & 256.8 & 87.3 & 261.2 & 82.3 & 0.168 \\
\hline Meat (g) & 48.6 & 36.4 & 58.0 & 44.6 & $<0.001$ \\
\hline Fish (g) & 71.5 & 51.2 & 86.1 & 61.0 & $<0.001$ \\
\hline All vegetables (g) & 216.2 & 129.4 & 276.7 & 151.8 & $<0.001$ \\
\hline $\begin{array}{l}\text { Green-yellow } \\
\text { vegetables (g) }\end{array}$ & 103.3 & 92.5 & 137.3 & 103.1 & $<0.001$ \\
\hline Other vegetables $(\mathrm{g})$ & 112.6 & 61.4 & 139.0 & 76.1 & $<0.001$ \\
\hline Fruit (g) & 156.7 & 115.1 & 249.2 & 157.5 & $<0.001$ \\
\hline Alcohol (g) & 23.5 & 19.6 & 4.3 & 11.3 & $<0.001$ \\
\hline
\end{tabular}

aDaily intake of energy and each nutrient was estimated from a food frequency questionnaire.

${ }^{\mathrm{b}}$ Ten men and 10 women with $\log _{\mathrm{e}}$-transformed energy intake values greater than 3 standard deviations from the mean energy intake per day by sex were excluded from the analyses for nutrition.

'Standard Deviation.

Table 5. Selected baseline psychosocial characteristics of participants, by sex

\begin{tabular}{lcrr}
\hline & Men & Women & $P$ value \\
\hline $\begin{array}{l}\text { TMIGa index } \\
\text { of competence, } n\end{array}$ & 1542 & 1516 & \\
$\quad$ Median (IQR $)$ & $12(11-13)$ & $13(12-13)$ & $<0.001$ \\
& 1537 & 1514 & \\
$\begin{array}{l}\text { Life Satisfaction Index-K, } n \\
\quad \text { Median (IQR) }\end{array}$ & $5(4-7)$ & $5(4-7)$ & 0.930 \\
$\begin{array}{l}\text { Geriatric Depression } \\
\text { Scale-15, } n\end{array}$ & 1538 & 1513 & \\
$\begin{array}{l}\text { Median (IQR) } \\
\text { Depressive tendency } \\
\text { (total score } \geq 6), n(\%)\end{array}$ & $310(20.2)$ & $363(24.0)$ & 0.018 \\
\hline
\end{tabular}

aTokyo Metropolitan Institute of Gerontology.

${ }^{b}$ Interquartile range.

\section{DISCUSSION}

To our knowledge, this is the first report of an age-specific, prospective cohort among a younger elderly population. Herein, we described the rationale and study design, and briefly presented the baseline demographic, lifestyle, clinical, and psychological characteristics of participants reaching the early-senescence age of 65 years.

Over the past 50 years, many cohort studies on aging and its related factors have been conducted in Japan and in western countries. ${ }^{13-12}$ Although these studies have evaluated various risk factors relevant to mortality and morbidity, in addition to changes in physical, psychological, and cognitive functions, the participants of these studies were people aged 70 years or older, ${ }^{7,9,11,13,14}$ or were of widely dispersed ages. ${ }^{10,15,16,18}$ The 
life table of the Japanese population (data available through the Internet, http://www.mhlw.go.jp/toukei/saikin/hw/life/ 20th/index.html $)^{39}$ shows that the death rate markedly accelerates after the age of 65. Thus, cohorts of older elderly people would be selectively composed of survivors of early senescence. In addition, detailed physical and psychological examinations would be overly challenging for the older elderly because of their relatively advanced functional deterioration. On the other hand, in cohorts comprising people aged 40 or 50 years, significant health events would be rare during the early follow-up period, resulting in a lack of statistical power. Another point to consider is that most Japanese employees retire between the age of 60 and 65, and their lifestyles dramatically change at this time. Our cohort allows us to investigate participant lifestyles and clinical or subclinical physical/psychosocial status at the middle of their seventh decade of life. These factors are likely to be important predictors of subsequent enduring physical and mental well-being.

Our cohort is rather unusual because it is composed of a uniform age-specific group of people. Age is one of the most important factors that affect health events. In epidemiological studies, therefore, multivariable analyses are performed that treat age as a covariate. However, the manner of age attribution is not necessarily linear, and some unadjusted age effects may remain. Our age-specific study design completely eliminates age-derived biases. To our knowledge, there are 2 other age-specific cohort studies of elderly people in Japan: the Koganei Study ${ }^{7}$ enrolled people aged 70 years as the study participants, and a study conducted by Kyushu Dental College ${ }^{9}$ registered elderly people aged 80 years as cohort members. Their response rates $(43.5 \%$ and $54.4 \%$, respectively) and measurements of lifestyle, activity level, quality of life, and physical and cognitive function were similar to those of our project; however, the target ages were higher. Our cohort comprises more than 3000 participants and is larger than other elderly cohorts, which should ensure the validity of our analyses. Moreover, this cohort is characterized by an annual 6-year consecutive entry-exit system. Every year, several hundred 64-year-olds enter the cohort as a similar number leave it. We therefore were able to invest less manpower in registration and baseline/outcome measurements than is necessary for the simultaneous entry system that is commonly used in community-based cohort studies.

Some study limitations warrant consideration. First, although our study was combined with a free medical checkup, the response rate was not high $(43.9 \%)$. In general, some differences in characteristics are found between respondents and nonrespondents. Elderly respondents are reported to be subjectively healthier and more satisfied with life than nonrespondents. ${ }^{40}$ Socioeconomic status might confound with participation in health checkups. ${ }^{41}$ Although we were unable to obtain any data on the health status of nonrespondents, our study participants, because they were respondents, probably
Table 6. Selected health-related characteristics in general Japanese population, by sex (summarized from data from nationwide surveys)

\begin{tabular}{|c|c|c|}
\hline & \multicolumn{2}{|c|}{ Age 60-69 } \\
\hline & Men & Women \\
\hline \multicolumn{3}{|l|}{ Lifestyle $^{a}$} \\
\hline Current smoker (\%) & 33.3 & 7.6 \\
\hline Current drinker $(\%)$ & 73.0 & 29.4 \\
\hline \multicolumn{3}{|l|}{ Medical status ${ }^{a}$} \\
\hline Obesity $(\%)^{c}$ & 29.7 & 29.9 \\
\hline Hypertension $(\%)^{d}$ & 67.7 & 55.9 \\
\hline Hyperlipemia $(\%)^{e}$ & 28.7 & 49.6 \\
\hline \multicolumn{3}{|l|}{ Dental status ${ }^{\mathrm{b}}$} \\
\hline Brushing $\geq 3$ times/day (\%) & 15.2 & 27.5 \\
\hline Number of teeth present $\geq 20(\%)$ & 65.3 & 61.7 \\
\hline \multicolumn{3}{|l|}{ Nutritional status ${ }^{a}$} \\
\hline Energy intake (kcal) & 2182.0 & 1769.0 \\
\hline Fat $(g)$ & 53.4 & 47.0 \\
\hline Protein (g) & 81.4 & 69.3 \\
\hline Carbohydrate (g) & 306.3 & 260.1 \\
\hline Meat (g) & 68.9 & 53.7 \\
\hline Fish (g) & 124.1 & 95.1 \\
\hline All vegetables (g) & 312.4 & 295.9 \\
\hline Fruits (g) & 151.9 & 177.8 \\
\hline
\end{tabular}

aNational Health and Nutrition Survey in Japan, 2004.

bSurvey of Dental Disease, 2005.

'Body mass index $\geq 25.0 \mathrm{~kg} / \mathrm{m}^{2}$.

'Systolic blood pressure $\geq 140 \mathrm{mmHg}$, diastolic blood pressure $\geq 90 \mathrm{~mm} \mathrm{Hg}$.

' Total cholesterol $\geq 220 \mathrm{mg} / \mathrm{dl}$.

had better health-related characteristics than did nonrespondents. To assess the representativeness of the participants in our cohort, we compared the participants' characteristics with data from several available nationwide surveys: the National Health and Nutrition Survey in Japan, 2004 (data available through the Internet, http://www.mhlw.go.jp/houdou/2006/ 05/h0508-1a.html), ${ }^{42}$ and the National Survey of Dental Disease in Japan, 2005 (data available through the Internet, http://www.mhlw.go.jp/topics/2007/01/tp0129-1.html). ${ }^{43}$ The condition of the present study participants was somewhat better than that of the general Japanese population aged 60 to 69 years (Table 6). The frequencies of smoking, alcohol consumption, obesity, and hypertension, for example, were slightly lower in the cohort members than in the general population, whereas that of hyperlipemia was higher in the cohort members. Although a low response rate might yield a non-negligible selection bias in descriptive epidemiology, the effects of such bias would be rather small in association analyses between outcomes and their risk factors in a cohort. Nevertheless, this possible bias should be taken into consideration when generalizing the study results.

Because we annually recruited the study participants from 1996 through 2005, our observations might have been affected by the passage of time. ${ }^{44}$ Issues related to this time trend will be addressed in a future article. 
As of April 2009, the enrollment of cohort members has been completed and follow-up health checks are ongoing. The NISSIN Project is a promising way to collect valuable information on well-being in this new era of longevity.

\section{ACKNOWLEDGMENTS}

We are greatly indebted to the Health Center and Hygiene Department of Nissin City for their generous cooperation in establishing and following the cohort. We also gratefully acknowledge the special efforts of the Nissin Medical and Dental Associations. This study was partially supported by a Grant-in-Aid for Scientific Research (15390197) from the Ministry of Education, Culture, Sports, Science and Technology of Japan. The authors report no financial conflict of interest.

\section{REFERENCES}

1. Vital Statistics of Japan 2005. Tokyo: Health and Welfare Statistics Association; 2007.

2. Population projections for Japan: 2001-2050 (with Long-range population projections: 2051-2100). Tokyo: Health and Welfare Statistics Association; 2002.

3. Laurin D, Verreault R, Lindsay J, MacPherson K, Rockwood K. Physical activity and risk factor of cognitive impairment and dementia in elderly persons. Arch Neurol. 2001;58:498-504.

4. Barberger-Gateau P, Letenneur L, Deschamps V, Peres K, Dartiques JF, Renaud S. Fish, meat, and risk of dementia: cohort study. BMJ. 2002;325:932-3.

5. Ganguli M, Dodge HH, Mulsant BH. Rates and predictors of mortality in an aging, rural community-based cohort: the role of depression. Arch Gen Psychiatry. 2002;59:1046-52.

6. Jorm AF. Is depression a risk for dementia or cognitive decline?: a review. Gerontology. 2000;46:219-27.

7. Yasumura S, Shibata $H$. The effect of aging on the electrocardiographic findings in the elderly-a 10-year longitudinal study: the Koganei Study. Arch Gerontol Geriatr. 1989;9:1-15.

8. Kwon J, Suzuki T, Kumagai S, Shinkai S, Yukawa H. Risk factors for dietary variety decline among Japanese elderly in a rural community: a 8-year follow-up study from TMIG-LISA. Eur J Clin Nutr. 2006;60:305-11.

9. Takata Y, Ansai T, Soh I, Akifusa S, Sonoki K, Fujisawa K, et al. Association between body mass index and mortality in an 80-year-old population. J Am Geriatr Soc. 2007;55:913-7.

10. Shimokata H, Ando F, Niino N. A new comprehensive study on aging-the National Institute for Longevity Sciences, Longitudinal Study of Aging (NILS-LSA). J Epidemiol. 2000;10:S1-9.

11. Kuriyama S, Hozawa A, Ohmori K, Shimazu T, Matsui T, Ebihara $\mathrm{S}$, et al. Green tea consumption and cognitive function: a cross-sectional study from the Tsurugaya Project 1 . Am J Clin Nutr. 2006;83:355-61.

12. Enoki H, Kuzuya M, Masuda Y, Hirakawa $Y$, Iwata M, Hasegawa J, et al. Anthropometric measurements of mid-upper arm as a mortality predictor for community-dwelling Japanese elderly: the Nagoya Longitudinal of Frail Elderly (NLS-FE). Clin Nutr. 2007;26:597-604.

13. Abbott RD, White LR, Ross GW, Masaki KH, Curb JD, Petrovitch H. Walking and dementia in physically capable elderly men. JAMA. 2004;292:1447-53.

14. Bruce ML, Seeman TE, Merrill SS, Blazer DG. The impact of depressive symptomatology on physical disability: MacArthur Studies of Successful Aging. Am J Public Health. 1994;84:1796-9.

15. Bowen ME, González HM. Racial/ethnic differences in the relationship between the use of health care services and functional disability: the health and retirement study (1992-2004). Gerontologist. 2008;48:659-67.

16. Koster A, Bosma H, Broese van Groenou MI, Kempen GI, Penninx BW, van Eijk JT, et al. Explanations of socioeconomic differences in changes in physical function in older adults: results from the Longitudinal Aging Study Amsterdam. BMC Public Health. 2006;6:244.

17. Lauretani F, Semba RD, Dayhoff-Brannigan M, Corsi AM, Di Iorio A, Buiatti E, et al. Low total plasma carotenoids are independent predictors of mortality among older persons: the InCHIANTI study. Eur J Nutr. 2008;47:335-40.

18. Ruggiero C, Metter EJ, Melenovsky V, Cherubini A, Najjar SS, Ble A, et al. High basal metabolic rate is a risk factor for mortality: the Baltimore Longitudinal Study of Aging. J Gerontol A Biol Sci Med Sci. 2008;63:698-706.

19. 2000 Population Census of Japan. Tokyo: Japan Statistical Association; 2005.

20. Wakai K, Egami I, Kato K, Lin Y, Kawamura T, Tamakoshi A, et al. A simple food frequency questionnaire for Japanese diet-Part I: development of the questionnaire, and reproducibility and validity for food groups. J Epidemiol. 1999;9:216-26.

21. Egami I, Wakai K, Kato K, Lin Y, Kawamura T, Tamakoshi A, et al. A simple food frequency questionnaire for Japanese diet-Part II: reproducibility and validity for nutrient intakes. J Epidemiol. 1999;9:227-34.

22. Koyano W, Hashimoto M, Fukawa T, Shibata H, Gunji A. Functional capacity of the elderly: measurement by the TMIG index of competence. Nippon Koshu Eisei Zasshi. 1993;40:468-74.

23. Koyano W, Shibata H, Nakazato K, Haga H, Suyama Y. Measurement of competence: reliability and validity of the TMIG index of competence. Arch Gerontol Geriatr. 1991;13:103-16.

24. Kutner B, Fanshel D, Togo AM, Langner TS. Five hundred over sixty: a community survey on aging. New York: Russel Saga Foundation; 1956.

25. Lawton MP. The Philadelphia Geriatric Center Morale scale: a revision. J Gerontol. 1975;30:85-9.

26. Neugarten BL, Havighurst RJ, Tobin SS. The measurement of life satisfaction. J Gerontol. 1961;16:134-43.

27. Koyano W, Shibata H. Development of a measure of subjective well-being in Japan. In: Vellas BJ, Albarede L, editors. Facts and Research in Gerontology 1994, Holmes Beach: Gaunt; 1994. p. 181-7.

28. Yesavage JA, Brink TL, Rose TL, Lum O, Huang V, Adey M, 
et al. Development and validation of a geriatric depression screening scale: a preliminary report. J Psychiatr Res. 1982-1983;17:37-49.

29. Niino N, Imaizumi T, Kawakami N. A Japanese translation of the geriatric depression scale. Clin Gerontol. 1991;10:85-7.

30. Almeida OP, Almeida SA. Short versions of the geriatric depression scale: a study of their validity for the diagnosis of a major depressive episode according to ICD-10 and DSM-IV. Int J Geriatr Psychiatry. 1999;14:858-65.

31. van Marwijk HW, Wallece P, de Bock GH, Hermans J, Kaptein AA, Mulder JD. Evaluation of the feasibility, reliability and diagnostic value of shortened versions of the geriatric depression scale. Br J Gen Pract. 1995;45:195-9.

32. Yatomi N. The factor structure and item characteristics of the GDS (Geriatric Depression Scale) short version in a Japanese elderly sample. Jpn J Gerontol. 1994;16:29-36 (in Japanese).

33. Honma A, Ishii T, Fukuzawa K, Tsukada Y, Hasegawa K, Mohs RC. Development of a Japanese version of Alzheimer's Disease Assessment Scale (ADAS). Jpn J Geriatr Psychiatry. 1992;3:647-55 (in Japanese).

34. Shinagawa F, Kobayashi S, Fujita K, Maekawa H. Japanese Wechsler Adult Intelligence Scale-Revised. Tokyo: Nihon Bunka Kagakusha; 1990 (in Japanese).

35. Tamakoshi A, Kawamura T, Wakai K, Ando M. Written informed consent for participation in a study and reduction in consent rate. J Epidemiol. 2008;18:291-4.

36. Imai E, Horio M, Nitta $\mathrm{K}$, Yamagata $\mathrm{K}$, Iseki $\mathrm{K}$, Hara $\mathrm{S}$, et al. Estimation of glomerular filtration rate by the MDRD study equation modified for Japanese patients with chronic kidney disease. Clin Exp Nephrol. 2007;11:41-50.
37. Levey AS, Coresh J, Balk E, Kausz AT, Levin A, Steffes MW, et al. National Kidney Foundation. National Kidney Foundation practice guidelines for chronic kidney disease: evaluation, classification, and stratification. Ann Intern Med. 2003;139:137-47.

38. Koushik A, Hunter DJ, Spiegelman D, Beeson WL, van den Brandt PA, Buring JE, et al. Fruits, vegetables, and colon cancer risk in a pooled analysis of 14 cohort studies. J Natl Cancer Inst. 2007;99:1471-83.

39. The 20th Life Tables. Statistics and Information Department Minister's of Health, Labour and Welfare Japan Government, 2007 (in Japanese).

40. Sugisawa H, Kishino H, Sugihara Y, Okabayashi H, Shibata H. Comparison of characteristics between respondents and nonrespondents in a national survey of Japanese elderly using six year follow-up study. Nippon Koshu Eisei Zasshi. 1999;46:551-62.

41. Mitsuhashi Y, Kishi R, Eguchi T, Miyake H, Maeda N. Factors associated with participation in medical chechups of the elderly at home comparison of 3 regions with different social backgrounds. Nippon Koshu Eisei Zasshi. 2003;50:49-61 (in Japanese).

42. The National Health and Nutrition Survey in Japan, 2004. Tokyo: Dai-ichi Publishing; 2006. (in Japanese).

43. Statistics of Oral Health, 2007. Tokyo: Ishiyaku Publishers, Inc.; 2007 (in Japanese).

44. Ma E, Iso $H$, Takahashi $H$, Yamagishi $K$, Tanigawa $T$. Age-Period-Cohort analysis of mortality due to ischemic heart disease in Japan, 1955 to 2000. Circ J. 2008;72:966-72. 